\title{
Research on the Anti-poisoning Properties of Zirconium Modified SCR Catalyst in Power Plants
}

\author{
Ning Zhao1, a Li Li , Siwei Pan, and Longhua Tang \\ ${ }^{1}$ Guangdong Power Grid Electric Power Research Institute Co., Ltd., Guangzhou, Guangdong \\ 510080, China \\ aemail: 15088050825@163.com
}

Keywords: SCR catalyst; anti-poisoning; zirconium modification

Abstract. The zirconium modified SCR catalysts were prepared by impregnation method, which exhibited high anti-poisoning properties. The optimal property was obtained by the zirconium modified SCR catalyst with $\mathrm{Zr} / \mathrm{V}$ molar ratio of 1.0. The catalyst samples were characterized by the methods of BET, X-ray diffraction (XRD) and Fourier transform infrared spectra (FT-IR). It was shown that the Brønsted acid sites on the catalyst surface were enhanced obviously, which was the main reason for the high anti-poisoning property of the zirconium modified catalysts.

\section{Introduction}

The phenomena of photochemical smog and acid rain will show a worsening trend recently. The $\mathrm{NO}_{x}$ emission of coal-fired power plants was about $50 \%$ of total $\mathrm{NO}_{x}$ emissions, and $\mathrm{NO}_{x}$ emission control will become the focus of the environmental protection in coal-fired power plants. The selective catalytic reduction (SCR) was the most common and effective technology to remove $\mathrm{NO}_{x}$ from flue gas, widely used in the power plants [1]. According to the statistics, the installed capacity of SCR system was about 687 million $\mathrm{kW}$ at the end of 2014.

SCR catalyst was the key to the SCR operator, and catalyst activity was directly related to the performance of the overall system [2]. With the increase of SCR running time, the deactivation of the SCR catalyst was inevitable. Alkali poisoning was one of the main reasons on catalyst deactivation at present [3]. Some recent reports indicated that the transition metal doping can improve the resistance to alkali poisoning for SCR catalysts to some extent [4]. With the SCR catalyst as our samples in this study, the zirconium modified catalysts were prepared by impregnation method, and the effect on the anti-poisoning properties of SCR catalyst has been investigated.

\section{Experimental}

Catalyst Samples. Honeycomb catalyst samples obtained from a commercial SCR catalyst were used in this study. The catalyst was consisting of $\mathrm{TiO}_{2}$ as a high surface area support and $\mathrm{V}_{2} \mathrm{O}_{5}-\mathrm{WO}_{3}$ as active catalytic components. The main parameters of the catalyst were showed in Table 1 .

Table 1 Main parameters of the SCR catalyst

\begin{tabular}{|c|c|c|}
\hline Item & Unit & Quantity \\
\hline Type of catalyst & - & Homogeneous Honeycomb \\
\hline Catalyst substrate material & - & titania-based ceramic \\
\hline Outer wall thickness & $\mathrm{mm}$ & 0.95 \\
\hline Inner wall thickness & $\mathrm{mm}$ & $0.59 \pm 0.05$ \\
\hline Cell opening & $\mathrm{mm}$ & 6.25 \\
\hline Cell pitch & $\mathrm{mm}$ & 6.87 \\
\hline Outer pitch & $\mathrm{mm}$ & $150 \pm 2.0$ \\
\hline
\end{tabular}

The zirconium modified SCR catalysts with the $\mathrm{Zr} / \mathrm{V}$ molar ratio of $0.1,0.3,0.5,1.0$ and 2.0 were prepared by impregnation method. Firstly, the catalyst samples with a size of 3 channel $\times 3$ channel $\times 200 \mathrm{~mm}$ were impregnated by different concentrations of zirconium oxynitrate in 3 hours. Then the samples were dried by air at $110^{\circ} \mathrm{C}$ in 12 hours, and roasted at $500{ }^{\circ} \mathrm{C}$ in 3 hours. The 
zirconium modified SCR catalysts were marked as $\mathrm{VWTi}+\mathrm{Zr}(\mathrm{x})$, where $\mathrm{x}$ referred to the $\mathrm{Zr} / \mathrm{V}$ molar ratio.

To simulate the process of potassium intoxication, the zirconium modified SCR catalysts were impregnated by potassium nitrate with the K/V molar ratio of 2.0, and the preparation process was the same as above. The potassium intoxication catalysts were marked as $\mathrm{VWTi}+\mathrm{Zr}(\mathrm{x})+\mathrm{K}(2)$.

Activity Measurement. The SCR Tester was a SCR micro-reactor for catalyst activity test. The schematic of SCR tester was shown in Fig.1. The system was composed of five parts, including inlet system, mixed heater, main reactor, flue gas analyzer and gas purification system. Inlet gas included $\mathrm{N}_{2}, \mathrm{NO}, \mathrm{O}_{2}, \mathrm{SO}_{2} \mathrm{H}_{2} \mathrm{O}$ and $\mathrm{NH}_{3}$, and inlet gas flow precisely controlled by a number of mass flow meters. Firstly, inlet gas passed through the mixed heater, to ensure adequate mixing and preheating. Then $\mathrm{NH}_{3}$ reacted selectively with $\mathrm{NO}$ in the main reactor. Finally gas exhausted after absorption and purification. Flue gas analyzer was set at inlet and outlet of the reactor, to measure the concentration of inlet NO and outlet NO.

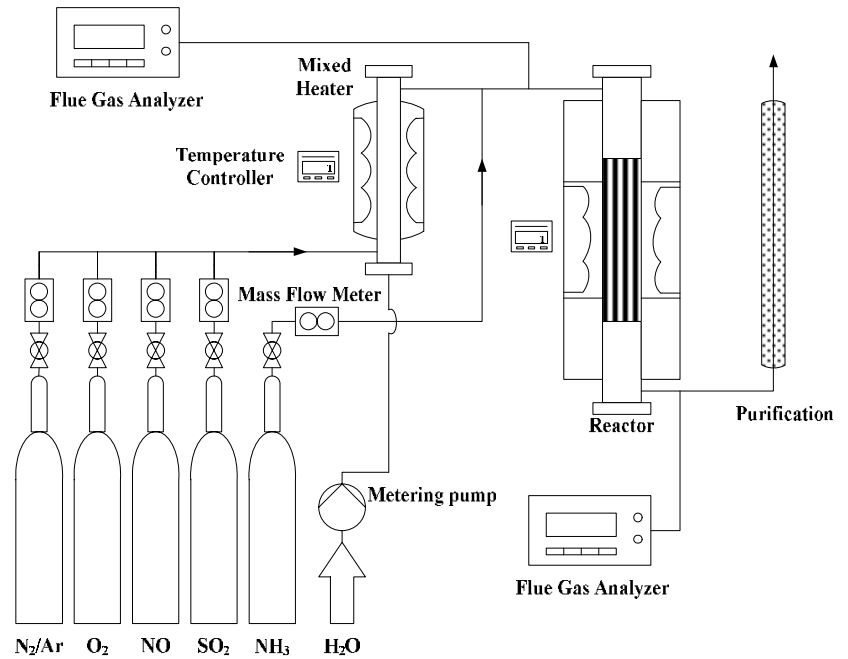

Fig. 1 Schematic drawing of SCR tester

Activity test was based on <Guideline for the Testing of DENO ${ }_{X}$ Catalysts> (VGB-R $302 \mathrm{He}$ ) [5]. Test temperature was set at $280 \sim 420{ }^{\circ} \mathrm{C}$, and other inlet flue gas parameters were shown in Table 2 .

Table 2 Set values of the inlet flue gas parameters

\begin{tabular}{|c|c|c|}
\hline Item & Unit & Set Value \\
\hline $\mathrm{O}_{2}$ & $\%$ & 3.9 \\
\hline $\mathrm{SO}_{2}$ & $\mathrm{mg} / \mathrm{Nm}^{3}$ & 1716 \\
\hline $\mathrm{H}_{2} \mathrm{O}$ & $\mathrm{Vol} \%$ & 9.6 \\
\hline $\mathrm{NO}$ & $\mathrm{mg} / \mathrm{Nm}^{3}$ & 410 \\
\hline $\mathrm{NH}_{3} / \mathrm{NO}$ & $\mathrm{mol} / \mathrm{mol}^{3}$ & 1.0 \\
\hline
\end{tabular}

The catalytic activity can be approximated by NO conversion $\eta$ :

$$
\eta=\frac{C_{0}-C_{1}}{C_{0}}
$$

where $\eta$ is the factional NO conversion; $C_{0}$ and $C_{1}$ are concentration of inlet NO and outlet NO, respectively.

Catalyst Characterization. The specific surface area was determined by BET methods using Tristar 3020 (Micromeritics, U.S.A.). The crystal phase structure of catalysts was examined by XRD using D8 Advance (Burker, Germany). The Fourier transform infrared spectra were used to analyze the adsorption properties of the catalysts with Nicolet 6700 (Thermo, U.S.A.). 


\section{Results and Discussions}

Activity Test Result. In order to compare the activities of the zirconium modified catalysts, the NO conversion of different catalyst samples were measured by SCR tester. Fig. 2 showed the NO conversion for the SCR of $\mathrm{NO}$ with $\mathrm{NH}_{3}$ over the catalysts at $280 \sim 420^{\circ} \mathrm{C}$. It can be seen from Fig. 2 that $\mathrm{NO}$ conversion over all the catalysts increased with increasing temperature. Compared with the fresh catalyst, the activities of the zirconium modified catalysts decreased slightly, but the NO conversion maintained above $90 \%$. It could be shown that the zirconium doping had little effect on the SCR catalyst activities.

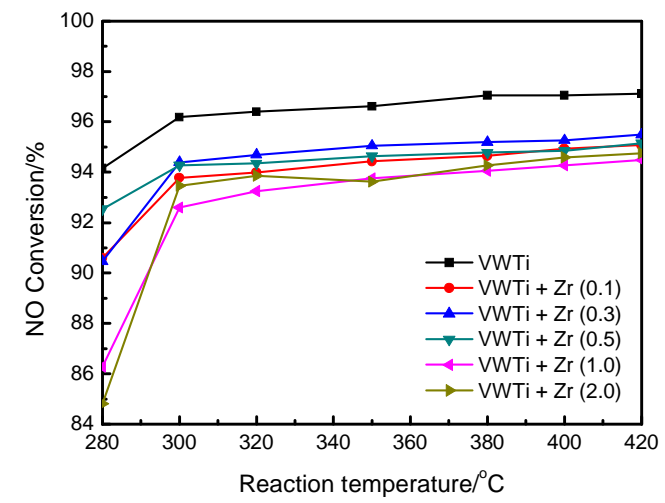

Fig. 2 Effect of zirconium concentration on the NO conversion over SCR catalysts

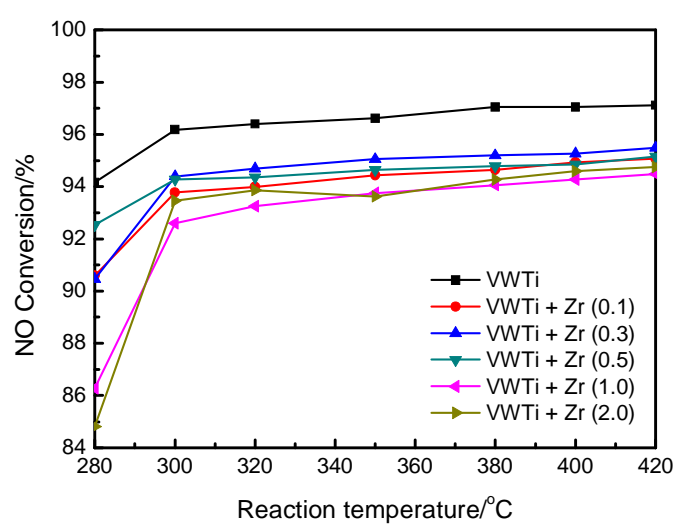

Fig.3 Effect of potassium intoxication on the NO conversion over SCR catalysts

The NO conversion of different potassium intoxication catalysts were shown in Fig. 3. It can be seen from Fig. 3 that the catalyst activities declined seriously due to the potassium intoxication. For the unmodified catalyst, the NO conversion reduced to about $75 \%$ at $350^{\circ} \mathrm{C}$, as shown in the Fig. 3 [WVTi+K(2)]. It should be noted that the catalytic activity of the catalyst samples was improved greatly after the zirconium doping, and the highest NO conversion (above 90\%) was obtained over $\mathrm{WVTi}+\mathrm{Zr}(1.0)+\mathrm{K}(2)$. Based on the results from Fig. 2 and Fig.3, it could be concluded that zirconium doping was favorable to improve the activity of the potassium intoxication catalysts.

BET Analysis. BET surface areas of different samples were summarized in Table 3. For the fresh catalyst, the BET surface area was determined to be $39.88 \mathrm{~m}^{2} / \mathrm{g}$. With the increase of the zirconium doping content, the BET surface area of the zirconium modified catalyst did not change significantly. Because of the large specific surface area of $\mathrm{ZrO}_{2}$, the catalyst pore blockage did not appear.

Table 3 BET surface areas of various catalysts

\begin{tabular}{|c|c|c|c|c|}
\hline Catalyst & VWTi & VWTi+・ Zr(0.1) & VWTi+Zr(0.5) & VWTi+Zr(1.0) \\
\hline $\mathrm{S}_{\mathrm{BET}} /\left(\mathrm{m}^{2} / \mathrm{g}\right)$ & 39.88 & 39.90 & 38.89 & 39.44 \\
\hline
\end{tabular}

XRD Analysis. The crystal phase structure of catalysts determined its catalytic activity. Most commercial SCR catalysts used $\mathrm{TiO}_{2}$ as a carrier. Generally, it was known that $\mathrm{TiO}_{2}$ anatase phase as the support of SCR catalyst was more active than $\mathrm{TiO}_{2}$ rutile phase [6]. XRD spectra of zirconium modified catalysts were shown in Fig. 4. For the various catalysts, the reflections provided typical diffraction peaks as attributive indicator of $\mathrm{TiO}_{2}$ anatase phase $\left(2 \theta=25.3^{\circ}, 37.8^{\circ}, 48.0^{\circ}, 53.9^{\circ}\right.$ and $55.1^{\circ}$ ). It meant that $\mathrm{TiO}_{2}$ in the catalysts existed in the form of anatase. It indicated that the crystal phase structure of this catalyst did not change. In addition, no visible phases of $\mathrm{V}_{2} \mathrm{O}_{5}$ and $\mathrm{WO}_{3}$ were observed in the XRD patterns. It revealed that amorphous $\mathrm{V}_{2} \mathrm{O}_{5}$ and $\mathrm{WO}_{3}$ highly dispersed on the surface of $\mathrm{TiO}_{2}$ carrier, which did not form crystal phase. 


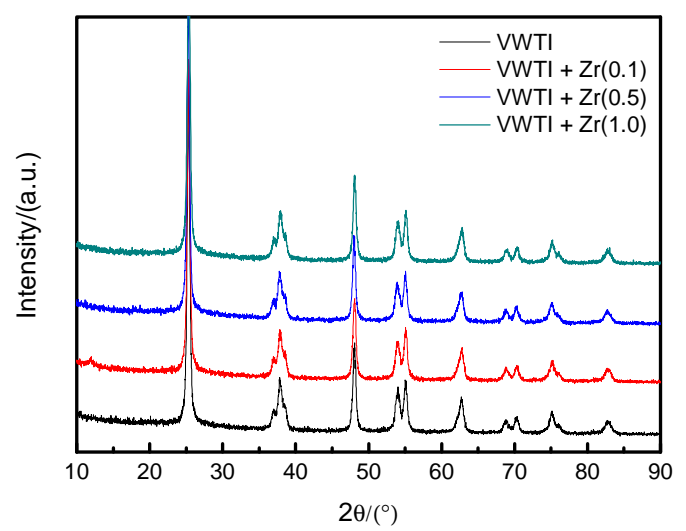

Fig. 4 XRD spectra of zirconium modified catalysts

FT-IR Analysis. $\mathrm{NH}_{3}$ adsorption was the essential step for the selective catalytic reduction [7]. FT-IR spectra of the various catalysts changed with time were shown in Fig. 5. The spectral bands at $1683 \mathrm{~cm}^{-1}$ and $1449 \mathrm{~cm}^{-1}$ correspond to the symmetric and anti-symmetric vibration of $\mathrm{NH}_{4}{ }^{+}$adsorbed on the Brønsted acid sites respectively [8].

For the fresh catalysts (Fig. 5 (a)), the $\mathrm{NH}_{4}{ }^{+}$characteristic peak appeared after $5 \mathrm{~min}$, enhanced gradually with the $\mathrm{NH}_{3}$ adsorption, and reached a maximum value after $30 \mathrm{~min}$. The $\mathrm{NH}_{4}{ }^{+}$ characteristic peak of the zirconium modified catalysts (Fig. 5 (b)-(d)) was a similar variation. It can be seen that the $\mathrm{NH}_{4}{ }^{+}$characteristic peak enhanced gradually with the increase of the zirconium doping content. It meant that the zirconium doping can increase the Brønsted acid sites effectively, and then improve anti-poisoning properties of SCR catalyst.

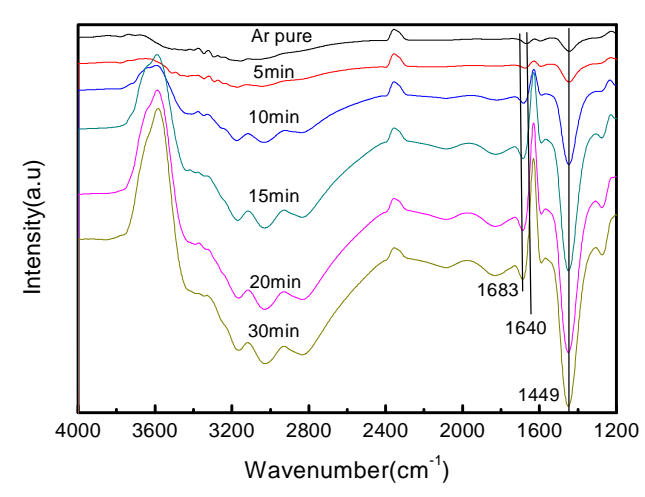

(a) VWTi

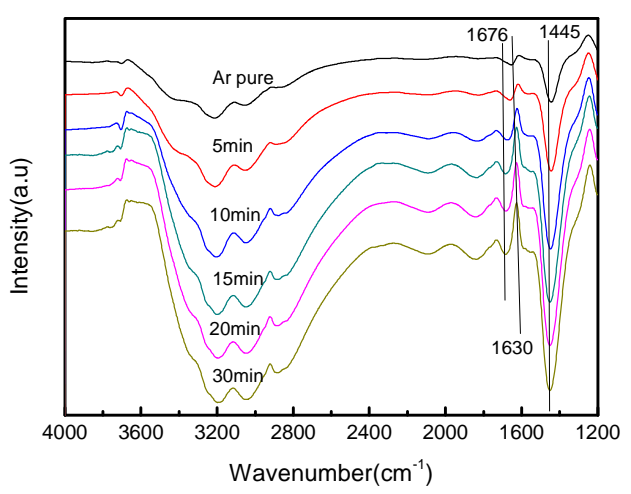

(c) $\mathrm{VWTi}+\mathrm{Zr}(0.5)$

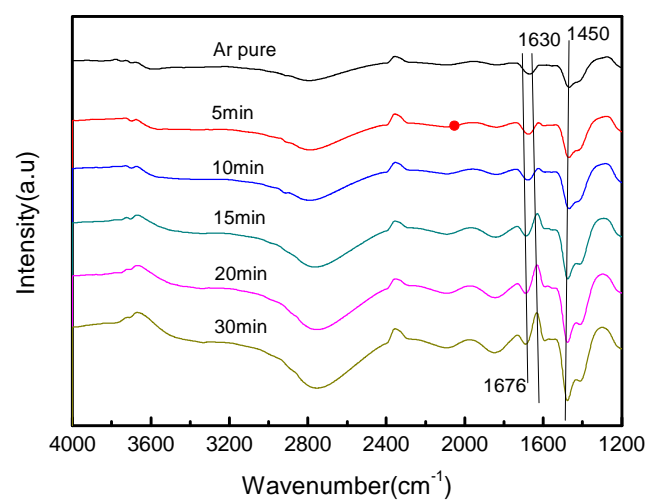

(b) $\operatorname{VWTi}+\operatorname{Zr}(0.1)$

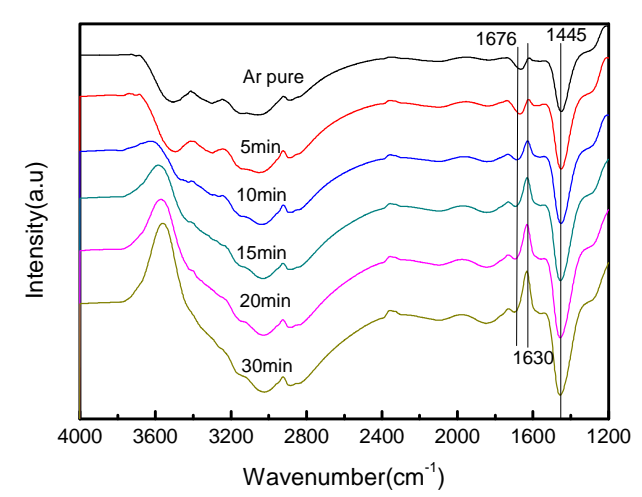

(d) $\operatorname{VWTi}+\operatorname{Zr}(\mathbf{1 . 0})$

Fig. 5 FT-IR spectra of the various catalysts changed with time 


\section{Conclusions}

The zirconium modified SCR catalysts exhibited high activity, which were prepared by impregnation method. The zirconium doping enhanced the resistance of SCR catalyst to alkali metal greatly. Among the zirconium modified SCR catalysts, $\mathrm{VWTi}+\operatorname{Zr}(1.0)$ showed the best resistance to potassium intoxication.

Based on the BET, XRD and FT-IR results, the surface area and the crystal phase structure of SCR catalysts was not changed by zirconium doping. The Brønsted acid sites on the catalyst surface were enhanced obviously, which was the main reason for the high anti-poisoning property of the zirconium modified catalysts.

\section{Acknowledgements}

This work was financially supported by China Southern Power Grid Science and Technology Project.

\section{References}

[1] Boxiong Shen, Jianwei Shi, Tingting Yang, et al: Chemical Industry and Engineering Progress Vol. 27(2008), p.64-67.In Chinese

[2] Kang Liu, Hong Yu, Hong Yu, et al: Guangdong Electric Power Vol. 22(2009), p.75-78. In Chinese

[3] Y. Zheng, A. D. Jensen and J. E. Johnsson: Applied Catalysis B Vol. 60(2005), p.253-264

[4] A. C. Larsson, J. Einvall, A. Andersson, et al: Energy Fuels Vol. 20(2006), p.1398-1405

[5] Information on http://www.vgb.org

[6] L. Baraket, A. Ghorbel, and P. Grange: Applied catalysis B Vol. 72(2007), p.37-43

[7] J. P. Chen and R. T. Yang: Journal of Catalysis Vol. 125(1990), p.411-420

[8] G. Ramis, L. Yi, and G. Busca: Catalysis Today Vol. 28(1996), p.373-380 